\title{
EL CONFLICTO COLOMBIANO: INCIDENCIA DE LA POLÍTICA DE SEGURIDAD DEMOCRÁTICA URIBISTA EN LA SEGURIDAD HUMANA
}

\author{
Unai Vázquez Puente \\ Euskal Herriko Unibertsitatea / Universidad del País Vasco EHU/UPV
}

http://dx.doi.org/10.5209/rev_NOMA.2014.v44.n4.49299

\begin{abstract}
Resumen.- El trabajo que nos ocupa realiza un análisis del conflicto colombiano partiendo desde el concepto Seguridad Humana, acuñado por el Programa de Naciones Unidas para el Desarrollo (PNUD), que centra la importancia de la seguridad en el Ser Humano; hasta la Seguridad Democrática de Álvaro Uribe Vélez, con una visión más estatocéntrica, durante sus dos mandatos continuados desde 2002 hasta 2010. Todo ello, estudiando el impacto en los desplazamientos internos de población civil dentro del país. En definitiva, pretende demostrar que la aplicación de la denominada Seguridad Democrática uribista tiene una incidencia negativa directa en la Seguridad Humana en materia de vulneración de Derechos Humanos fundamentales y especialmente en el aumento del número de desplazados internos.
\end{abstract}

Palabras clave.- Seguridad Democrática, Seguridad Humana, Derechos Humanos, Desplazamiento, Alternativas.

\section{Introducción}

El conflicto armado colombiano, plasma perfectamente el cambio acaecido en la tipología de los conflictos armados de la posguerra fría: conflictos internos, guerras civiles, basadas en factores económicos y políticos que se van pervirtiendo por el propio actuar de la guerra. La irrupción de terceros actores entre el gobierno y las guerrillas insurgentes, dígase el paramilitarismo o los cárteles del narcotráfico son buena muestra de ello. Otro de los cambios globales que se vislumbran en el conflicto colombiano es la evolución del concepto de amenaza, centrado a día de hoy en el terrorismo; percepción aprovechada por el gobierno de Colombia para, tras el 11 de septiembre de 2001, catalogar a los grupos insurgentes como terroristas en las listas organizadas a nivel internacional. En definitiva, se ha dado un avance del concepto de seguridad menos centrado en el Estado y más en las personas, que el Estado Colombiano trata de resistir mediante la Seguridad Democrática; en un territorio donde la afección humana, en modo de desplazamiento interno supera la cifra de cuatro millones de personas, una de las cifras más alta y sostenida en el tiempo a nivel mundial. Pese a todo, la atención mediática y académica es mínima en comparación con otras latitudes del planeta, donde los regímenes imperantes no son avalados por los países hegemónicos del Norte. Colombia, mientras tanto, es considerada una de las democracias modélicas del subcontinente latinoamericano.

El concepto de Seguridad Humana salta a la agenda pública con el informe del Programa de Naciones Unidas para el Desarrollo (PNUD) de 1994, que relaciona la seguridad con las personas, con los individuos en lugar de hacerlo con los territorios que estos habitan. Es decir que rompe el estatocentrismo clásico en seguridad para 
fijar el centro de atención en los Seres Humanos. Este concepto está caracterizado por la multidimensionalidad, ya que se entiende desde la capacidad de cumplir con las seguridad en ámbitos tan dispares como: la economía, alimentación, salud, medio ambiente; así como la seguridad a nivel individual o personal, a nivel comunitario y en el aspecto político. Para su mediación o alerta, propone el uso de indicadores objetivos y subjetivos como la angustia humana, las tasas de criminalidad, los accidentes de tráfico o la estratificación en los ingresos (dentro del país, más que entre países).

En cualquier caso, hay que tener en cuenta que existen dos posiciones principales en lo que respecta al concepto o visión de la Seguridad Humana, la reducida y la amplia. La perspectiva reducida, pone enfatiza en la amenaza violenta, descartando todas las demás que considera pueden dificultar la aplicabilidad de derechos que garanticen la seguridad humana. Es una visión más pragmática, defendida por autores como Krause, Mack Macfarlane. "Ponen el acento en los peligros que pueden afectar a la vulnerabilidad de las personas y su bienestar ubicando esta realidad bajo la rúbrica de la seguridad". Esta visión es defendida también por Estados como Canadá, que define la Seguridad Humana como "libertad respecto de las amenazas de los derechos, seguridad y vida de la gente", priorizando la protección de civiles y la reducción del costo humano de los conflictos armados; el soporte para las operaciones de paz; la prevención y solución de conflictos; la gobernabilidad y el establecimiento de normas democráticas y de derechos humanos; la seguridad pública y la articulación de instrumentos internacionales para hacer frente a las amenazas del crimen organizado internacional.

La visión amplia, defendida por autores como Leaning, Alkire, Thakur Axwothy, Wilson y Eriksen, así como por las Naciones Unidas, va más allá de la prioridad de la protección frente a la amenaza y "sugieren la importancia de temas como los desastres medioambientales, las enfermedades, la pobreza, los riesgos tecnológicos y alimentarios, la desintegración de las redes sociales entre otros". Así, la Comisión de Seguridad Humana de Naciones Unidas da la siguiente definición:

Seguridad Humana consiste en proteger la esencia vital de todas las vidas humanas de una forma que realce las libertades humanas y la plena realización del ser humano. Significa proteger las libertades fundamentales: libertades que constituyen la esencia de la vida. Significa proteger al ser humano contra las situaciones y amenazas críticas (graves) y omnipresentes (generalizadas). Significa utilizar procesos que se basan en la fortaleza y las aspiraciones del ser humano.

En el mismo sentido amplio, Japón define la Seguridad Humana como "la preservación y protección de la vida y la dignidad del ser humano (...) que solo será lograda sí cada persona tiene confianza en una vida libre del miedo y libre de la necesidad".

En cualquier caso, la aplicación del uso restringido sería suficiente para garantizar la Seguridad a la población civil en Colombia que sufre los atropellos del uso legítimo de la violencia por parte de las Fuerzas Armadas del Estado. Pero la realidad es que los países del hemisferio Sur se sitúan en una visión restringida de la seguridad, es decir, separan la agenda de desarrollo de aquella que tiene relación con la defensa y la seguridad interior. Así "diferencian fuertemente entre estas dos últimas, las que responden a marcos normativos diferenciados. De esta forma se evita militarizar la 
agenda de desarrollo y las respuestas a las demandas y protestas sociales"; algo que Colombia, siguiendo el modelo estadounidense que ignora el concepto de Seguridad Humana, ha seguido milimétricamente, permitiéndose así mantener un sentido estatocéntrico de la seguridad y catalogando como terrorista toda reivindicación de las mejoras relacionadas con el desarrollo o con la visión amplia de Seguridad Humana. Como remarca Karlos Pérez de Armiño, la Seguridad Humana:

Asume una visión amplia y estructural de las causas de la inseguridad en y los conflictos, asociados a la vulnerabilidad socioeconómica, la mala gobernación y otros problemas de desarrollo. En este sentido, el enfoque de la seguridad humana tiene más capacidad que los actuales, por cuanto estas son esquemas clásicos para explicar las guerras civiles económico.

Lo que explica por sí mismo el rechazo de Colombia a este termino, y sobre todo al desarrollo y cambio de paradigma en defensa que supone el mismo.

\section{Contextualización del conflicto colombiano.}

En realidad, el denominado conflicto colombiano nace desde el momento mismo del nacimiento de Colombia como república independiente del Reino de España. A partir de este momento nace un sistema bipartidista que se volvería tradicional y excluyente y que sembraría el caldo de cultivo para el nacimiento de organizaciones armadas de liberación nacional, que en un principio poco tenían que ver con la ideología de izquierda, ya que provenían de corrientes liberales en 1950. En 1953, tras un golpe de Estado, asume en el poder Gustavo Rojas Pinilla, quien busca el desmantelamiento de las guerrillas liberales mediante la amnistía y la apertura a la participación política. Así, "Las Fuerzas Armadas Revolucionarias de Colombia (FARC), traicionadas por la dirigencia de su partido, pronto acogieron la ideología marxista-leninista que las acercó al Partido Comunista Colombiano". Posteriormente, nacerían nuevos grupos guerrilleros como el Ejercito de Liberación Nacional (ELN), más vinculado a la teología de la liberación de origen cristiano y al calor de la revolución Cubana. En los años 70 nacerá el M-19, como guerrilla urbana y origen intelectual, quienes se desmovilizarán en 1990. Entre finales de los años setenta y principios de los ochenta, se sitúa el nacimiento de los grupos paramilitares, supuestamente como autodefensas campesinas frente a las guerrillas, pero que terminarán sirviendo a los intereses de los terratenientes y posteriormente del narcotráfico de cocaína. En definitiva, tenemos multitud de actores armados, legales e ilegales donde como remarca Salamanca:

El ejercito nacional, dentro de sus funciones de preservación del orden y la seguridad lescoloca en una posición en la que su enemigo -supuestamente- es doble: las guerrillas y paramilitares. Pero por otra parte, no es secreto que, al menos en sus orígenes, y en casos más recientes y no precisamente esporádicos, se ha dado una colaboración entre las fuerzaslegales del Ejercito y las bandas paramilitares para combatir a lo que se podría ver como un enemigo común: las guerrillas.

Con todo ello, el conflicto colombiano cuenta con unas características comunes y transversales a lo largo de su duración, pese a que las razones para su mantenimiento hayan variado sustancialmente: 
- La acelerada concentración de la propiedad de la tierra, acelerada en un principio por los cultivos cafeteros y por el narcotráfico y la industria ganadera (en manos paramilitares) después.

- El colapso parcial del Estado en algunas regiones y presencia mínima del mismo en muchas otras.

- Masivo desplazamiento forzado de campesinos.

- Apertura de las fronteras agrícolas del país por la migración interna de personas del campo al campo (forzada), y la concentración en las ciudades por la migración de los campos a los centros urbanos.

Al finalizar el mandato de Álvaro Uribe, según la Red de Hermandad y Solidaridad con Colombia, existían más de cuatro 4,5 de desplazados forzosamente, 62.000 desaparecidos, 3.000 ejecuciones extrajudiciales, el $70 \%$ de la población en la pobreza y el tercer puesto en el ranking de la desigualdad económica; con 6,5 millones de hectáreas despojadas al campesinado y el $52 \%$ de la tierra en manos del $1 \%$ de los propietarios. Todo ello pese a que "Colombia es el tercer mayor receptor de ayuda extranjera de Estados Unidos después de Israel y Egipto", dinero que ha sido utilizado sistemáticamente para la denominada lucha contrainsurgente, camuflada en diferentes momentos como lucha contra el narcotráfico y que se ha traducido en la última década en Plan Colombia en 1999 con el presidente Andrés Pastrana y paralelo al fracasado proceso de paz abierto con las FARC (Conversaciones del Caguan); el posterior Plan Patriota (2002); y la Seguridad Democrática del presidente Uribe en 2003. Planes, todos, mediante los que se ha avalado la vulneración de los Derechos Humanos bajo la vertiente de la securitización.

\section{La Seguridad Humana en Colombia y la amenaza a los derechos humanos. De las garantías legales a la violación de las mismas.}

Si anteriormente planteábamos que la Seguridad Humana en sentido amplio comprende desde la seguridad económica hasta la de la salud, ambiental, política, etc., es decir, la seguridad frente a la necesidad; en Colombia, centrándonos únicamente en la denominada seguridad frente al temor, es decir, el sentido estricto, observaremos que está es incumplida sistemáticamente. El problema es que, si bien esta vulneración de los derechos humanos se da por parte de todos los agentes implicados, es especialmente grave la sufrida por parte del Estado mediante la Fuerzas Armadas y su no cumplimiento del Derecho Internacional Humanitario (DIH). En general se puede considerar que las leyes colombianas son sobradamente garantistas:

Colombia ha suscrito los Cuatro convenios de Ginebra de 1949 y los protocolos adicionales de 1977, siendo todos ellos leyes vigentes en el país. Así las cosas, en el caso colombiano se aplican las normas del protocolo II adicional y del artículo 3 común. Colombia, mediante la Ley 5 de 1960, convirtió en Ley de la República los cuatro Convenios de Ginebra: posteriormente, en 1983, adhirió al Protocolo I y, a través de la Ley 171 de 1994 convirtió en ley el texto del Protocolo II adicional de 1977. Además, en la reforma constitucional de 1991 se incluyo el DIH en el marco constitucional. Otras posibilidades legales las da el hecho de que varias infracciones contra el DIH aparecen tipificadas como delitos en el Código Penal Militar. 
En definitiva, la Fuerza Pública está obligada por ley (constitucional y Código Penal Militar) a cumplir con el DIH. Pero la realidad es bien diferente, por poner un ejemplo vivido en carne propia, en la localidad de Mompox, en el Magdalena Medio, zona controlada mayoritariamente por los grupos paramilitares agrupados en las Autodefensas Unidas de Colombia (AUC), cuando participaba en una marcha que conmemoraba el 90 aniversario de la "Campaña Admirable" realizada por Bolívar previamente a la liberación de Caracas; observamos como los militares, que supuestamente estaban presentes para garantizar nuestra seguridad, se repartían en grupos de 4 a 6 , coordinados siempre por un individuo no uniformado, que presumiblemente era paramilitar. Pero la mayor amenaza a los Derechos Humanos y a la Seguridad Humana es la falta de garantías del Derecho a la Vida. Así, durante el primer periodo de Álvaro Uribe, entre 2002 y 2006, "11.292 personas fueron asesinadas o desaparecidas fuera de combate por violencia sociopolítica y se incrementaron dramáticamente los casos de participación directa de agentes estatales. En el mismo periodo 908 personas fueron muertas o desaparecidas por acciones directas de servidores públicos".

El programa de la Universidad de Simon Fraser para la medición de la Seguridad Humana desde el ámbito restrictivo, mide la misma utilizando en base a las muertes causadas por la violencia asociada a conflictos armados y a acciones criminales. Pero en el caso de Colombia tanto en el Estado como en la sociedad civil se han adelantado proyectos que buscan medir algunas de estas formas de violencia (anteriormente mencionábamos algunos datos, como el secuestro, la desaparición forzada, las violaciones a los derechos humanos, el desplazamiento forzado, las ejecuciones extrajudiciales, etc.); "sin embargo, no se conocen esfuerzos que busquen medir, a través de diferentes tipos de violencias o riesgos, la situación de inseguridad par alas personas en Colombia". En definitiva, el análisis cuantitativo de la Seguridad Humana en Colombia es bastante escaso, y el poco que se ha realizado obedece únicamente a los índice de criminalidad urbana, con una preocupación de la Seguridad Humana, más relacionada con el bienestar y la tranquilidad de las clases medias y altas que las habitan, que las consecuencias en Seguridad Humana derivadas del conflicto. Así, "el primer esfuerzo, el de la Fundación Seguridad y Democracia (2006), es un índice de seguridad urbana que evalúa actividades delictivas que tienen incidencia en la vida, la libertad y el patrimonio de las personas, en un cálculo que hace para 27 ciudades del país".

Este enfoque, o falta de análisis desde la perspectiva de la Seguridad Humana, responde a la visión clásica, estatocéntrica, de la seguridad por parte del Estado colombiano. Desde su punto de vista, la responsabilidad de proteger recae en sus manos y la amenaza la sitúa en los grupos insurgentes -posteriormente calificados de terroristas- y en todo lo que considere sus colaboradores o base logística, ideológica o propagandística; al que no cabe otro remedio que combatir con todas las fuerzas y recursos por encima de conceptos como la Seguridad Humana o los propios Derechos Humanos. Para ello, a partir de 2003, comenzado ya el primer mandato de Uribe, llevará a cabo la estrategia de mano dura que le hizo ganar las elecciones bajo el término de "Seguridad Democrática". De tal modo que "la mencionada política de Seguridad Democrática parte del supuesto de que en Colombia no hay un conflicto armado, sino ataques de grupos terroristas contra el Estado y la población (...); bajo la conocida lógica de que quien no está conmigo está contra mi". En definitiva, concluyen que la amenaza a Seguridad Humana 
proviene de a guerrilla, por lo que hay que combatirla hasta hacer desaparecer la amenaza.

\section{La Seguridad Democrática frente a la Seguridad Humana: del nacimiento del concepto a la aplicación por Álvaro Uribe Vélez.}

Como destaca Pérez de Armiño, "Existe el riesgo de que los ejércitos y los gobiernos manipulen el concepto (de seguridad humana) a fin de justificar una cierta militarización de la gestión de diferentes problemas", esto es precisamente lo que ocurre en el caso colombiano, que si bien no utiliza el término asiduamente, si se aprovechó del mismo para introducir la denominada Seguridad Democrática ya que, el mismo, nace del concepto de seguridad humana.

La Seguridad Democrática, como termino que intenta marcar una visión diferente del concepto de seguridad, surge en América Central en el contexto de la posguerra fría y del fin de los conflictos o guerras civiles acaecidas (entiéndase El Salvador, Guatemala y Nicaragua en el momento en que el Frente Sandinista pierde las elecciones). Su objetivo era -supuestamente- la búsqueda de construir sociedades más equitativas y consolidar democráticas a mediados de los noventa. Así, está "inspirado, entre otros, en los trabajos de la Comisión Sudamericana de Paz. Este concepto de seguridad está influido por el enfoque de seguridad humana, que otorga prioridad y centralidad a la protección de la persona humana a través del respeto a los Derechos Humanos". En definitiva, el Tratado Marco de Seguridad Democrática en Centroamérica se firma en Honduras en 1995, un año después de que el PNUD acuñara el término de Seguridad Humana. El tratado tenía los siguientes objetivos o características:

- La democracia como base de la Seguridad Democrática: en una era global poscomunista, y en la que en Centroamérica, particularmente, habían fracasado los planteamientos y guerrillas de izquierda, caracterizándose por la paz liberal.

- Seguridad es respeto a los Derechos Humanos: teniendo en cuenta, que previamente, en la época de la guerra fría y de las revoluciones populares centroamericanas la vulneración de los Derechos Humanos fue sistemática, justificada e impulsada por el hegemón estadounidense que combatía dichas guerrillas.

- La Seguridad Democrática está altamente inspirada en la Seguridad Humana. Así, en Tratado afirma que "la seguridad democrática es inseparable de la dimensión humana" y la prioridad de la región es erradicar la pobreza y garantizar condiciones de vida digna a cada uno de los habitantes.

- $\quad$ Reforma de la fuerza pública: para adaptarse al cambio de modelo de la seguridad democrática, y que responde principalmente a las necesidades de reinserción de los guerrilleros, tras los acuerdos de Paz en El Salvador, que conformarán junto a exmilitares progubernamentales la Policía Nacional Civil.

Pero si en el caso de la Seguridad Democrática en Centroamérica, esta nace en el contexto de Negociaciones de Paz relativamente exitosas, el concepto en Colombia nació "en un marco caracterizado por el desencanto con el proceso de negociaciones entre el gobierno de Andrés Pastrana y las FARC (...) que el candidato presidencial en ese momento, Álvaro Uribe, busca situar como parte de la guerra contra el terrorismo"; es decir, con una estrategia antagónica con lo planteado en Centroamérica. 
Por todo ello, podríamos decir que la mencionada política de Seguridad Democrática es la estrategia gubernamental que tiene como base ubicar el conflicto interno armado colombiano en la cruzada mundial contra el terrorismo. De este modo, busca un nuevo término, que le acerque al concepto de Seguridad Humana, pero sin las implicaciones de protección de los Derechos Humanos que ella conlleva; para poder priorizar la mano dura contra las guerrillas considerando a las mismas responsables de la falta de seguridad que el Estado que con la ayuda de la sociedad civil debe conseguir. Así, en el documento "Política de Defensa y Seguridad Democrática", en propio Uribe define el concepto y sus objetivos con respecto al mismo:

La Seguridad Democrática se diferencia de las concepciones de seguridad profesadas por regímenes autoritarios, partidarios de la hegemonía ideológica y la exclusión política. Este gobierno no hace suyas las concepciones de otras épocas como la "Seguridad Nacional" en América Latina, que partía de considerar a un grupo ideológico o partidario como "enemigo interno".

Resulta especialmente llamativo el intento de distinción de los regímenes autoritarios, en un concepto que, en principio, proviene del concepto de Seguridad Humana. Podría decirse que cabe aplicar el refrán: dime de presumes y te diré de que careces. En cualquier caso, las amenazas que plantea el documento son: el terrorismo; el negocio de las drogas ilícitas; las finanzas ilícitas; el trafico de armas; el secuestro y la extorsión; y, por último, el homicidio. Destaca además como prioritario, para la eliminación de dichas amenazas, la consolidación del control estatal del territorio y el mantenimiento de una capacidad disuasiva; visiones todas ellas muy relacionadas con la visión de la "Seguridad Nacional" estatocéntrica de la que presume distanciarse.

En general, los datos oficiales hablan del éxito de la implementación de dicha política:

El Ministro de Defensa informó, a principios del mes de enero de 2004, que durante el año anterior se registraron 22.969 homicidios, $20 \%$ menos que los reportados en todo el año 2002. Las masacres presentaron una reducción del $39 \%,(\ldots)$ y los secuestros se redujeron en un 32\% (2.043 en 2003 frente a 2.986 en 2002). Los casos de secuestros en retenes ilegales descendieron en un $60 \%$. Los casos de terrorismo también muestran una tendencia a la baja, al pasar de 1.645 eventos en el año 2002 a 846 en el 2003, es decir, un 49\% menos.

Pero estos datos oficiales, que están enfocados en la lucha contrainsurgente, no recogen los números de las violaciones de derechos humanos perpetrados precisamente por quienes defienden esas cifras. Por ejemplo:

Se mantiene un número de 12 personas muertas o detenidas-desaparecidas al día a causa de la violencia socio-política, seis de ella por fuera del combate. El $80 \%$ de los casos reportados son responsabilidad del Estado. Entre el 7 de agosto de 2002, día de la posesión presidencial de Uribe, hasta junio de 2005, se registraron cerca de 6.000 detenciones arbitrarias.

En definitiva, la otra lectura que nos deja el objetivo y estrategia de la Seguridad Democrática que se plantea en la Carta Presidencial es que la recuperación de 
territorio para el desarrollo de "proyectos productivos" se convierte en la escusa para el despojo de tierras o la legalización de facto del desplazamiento forzado. Así, mediante la fase denominada de "recuperación y consolidación" permite a los miembros de la fuerza pública "judicializar a los miembros de las organizaciones terroristas" que en la práctica se vuelve contra toda la población discordante con el actuar de estas mismas fuerzas. Y, por último, para la "consolidación estatal del territorio" se permite la implementación de "proyectos sostenibles a medio y largo plazo" que se traducen en la posesión de la tierra, por parte de transnacionales para la plantación de Palma africana.

En conclusión, el objetivo de la Seguridad Democrática es la creación de un Estado Comunitario, donde toda la población se identifique con el mismo y socializar así las responsabilidades institucionales, especialmente en materia de defensa y seguridad; una especie de Gran Hermano orwelliano, donde la desterritorialización o el desplazamiento forzoso es un mecanismo de control.

\section{La incidencia pragmática de la Seguridad Democrática en el desplazamiento forzoso. Amenazas y alternativas desde la Seguridad Humana.}

Según informa el Alto Comisionado de Naciones Unidas para los Refugiados (ACNUR), Colombia es uno de los países del mundo con mayor número de desplazados internos del mundo. Hasta mayo de 2011 el Gobierno de Colombia ha registrado a más de 3,7 millones de desplazados internos, pero otras ONG como la Consultoría para los Derechos Humanos y el Desplazamiento (CODHES) elevan la cifra hasta los 5 millones, contando únicamente desde la década de los ochenta. Estás cifras, suponen respectivamente entre el 4 y el $10 \%$ de la población del país en la totalidad del territorio, de tal modo que "de los 1.098 municipios del país, 1067 registraron casos de desplazamiento interno,(...) el 68\% del desplazamiento está concentrado en 150 municipios y (...) es una realidad presente en todos y cada uno de los departamentos del país".

Según en Gobierno Colombiano, la Seguridad Democrática es:

Una política para la protección de la población. La prevención del desplazamiento forzoso junto con la facilitación del retorno de la población desplazada a sus lugares de origen es uno de los cinco objetivos específicos que corresponden al objetivo estratégico Protección de la Población.

Pero la realidad es que no hay ningún plan específico que luche contra el desplazamiento forzado. El gobierno se limita a supeditar la seguridad humana de las personas, haciendo una correlación por la que a mayor control del territorio del Estado por parte de las fuerzas de Seguridad, mayores garantías para el no desplazamiento de la población. Así se demuestra en un reportaje hecho por el programa "En portada" de TVE, en 2010, al final del mandato de Álvaro Uribe; donde entrevista a Diego Molano, director de la Agencia Presidencial para la Acción Social, agencia encargada del registro y atención a los desplazados por el conflicto. En dicha entrevista, Molano afirma que:

Quien genera el desplazamiento en Colombia en un $27 \%$ son las FARC, entre el 18 
y $21 \%$ las autodefensas. (...) La población estaba inerme ante las presiones de los grupos. Lo que ha hecho el Gobierno es llevar sus fuerzas (a todo el territorio del Estado), es la primera parte de la prevención, es la autoridad legítima con el monopolio de las armas. Permite dar garantías. El principal derecho en la vida es la movilidad y la integridad.

Lo que Molano, cuando destaca los porcentajes de la incidencia de los actores armados en el desplazamiento, no esta teniendo en cuenta son los datos relativos a las fuerzas de Seguridad del Estado, y que ya adelantábamos al hablar en el apartado anterior de los datos de la Seguridad Democrática en Colombia: donde se mantiene un número de 12 personas muertas o detenidas-desaparecidas al día a causa de la violencia socio-política, seis de ellas por fuera del combate; el $80 \%$ de los casos reportados son responsabilidad del Estado y Entre el 7 de agosto de 2002, día de la posesión presidencial de Uribe, hasta junio de 2005, se registraron cerca de 6000 detenciones arbitrarias.

Resulta evidente, por tanto, que el Gobierno de Uribe y la política de Seguridad Democrática ignoran el papel activo del Estado en la falta de Seguridad Humana y concretamente en su influencia en la creación de desplazamiento forzoso de la población civil. Así, atendiendo a los datos, el resumen del Informe del 2009, de CODHES El desplazamiento forzado en los tiempos de Seguridad Democrática, señala que "durante el periodo 2002-2009 la cifra de desplazados asciende a 2.412.384 personas. Lo que quiere decir que el $49 \%$ de las personas fueron expulsadas de sus tierras durante el gobierno de Uribe". Además, observando la tabla realizada por la misma fuente respecto a el número de desplazados forzosos anuales en Colombia, vemos que en 2003, primer año de gobierno de Uribe, el numero de desplazados fue de 207.607; en 2004 era de 287.581; en 2005 de 310.387; así, pese a que hay que tener en cuenta que los datos inmediatamente anteriores a la toma de posesión de Uribe en 2002 eran de 412.000 desplazados, este es el pico más alto registrado en los últimos 20 años, y que la media de desplazamientos anuales se sitúa en los mismos datos que en las legislaturas de Uribe y su Seguridad Democrática. Por tanto, resulta imposible catalogar la política de Seguridad Democrática como una oportunidad para la Seguridad Humana.

Frente a esta situación, cabe destacar que resulta difícil encontrar alternativas al desplazamiento forzado por las amenazas, la extorsión, el robo de tierras y el asesinato, sobre todo cuando este es impulsado por el propio Estado. Pero en los últimos años, se ha dado una experiencia que podría catalogarse como un modelo de autodeterminación para la Seguridad Humana. Así, desde la resistencia civil, a principios de la década de los noventa, surgió la decisión colectiva de comunidades de separarse de la lógica del conflicto mediante el rechazo a la colaboración con los actores armados, declarándose Comunidades de Paz o Refugio Campesino Humanitario. El más emblemático y pionero fue la Comunidad de Paz de San José de Apartadó. Está comunidad es significativa puesto que fue creada en el departamento de Antioquia, cuando el después presidente Álvaro Uribe era gobernador. En aquel entonces, Uribe contaba con una propuesta para la colaboración de la población civil como informantes de la fuerza pública, que serviría de base para su posterior política de Seguridad Democrática. Dicha propuesta se basaba en "declarar mediante decreto algunos municipios como 'zonas neutrales', con base a una concepción de la neutralidad que promovía la no-cooperación con los actores armados ilegales y la cooperación con las Fuerzas Armadas del Estado". 
Al declarar San José de Apartadó su intención de no colaborar con ningún agente armado, fue rechazada por Uribe como zona neutral. La reacción a este tipo de iniciativa, por parte de los actores armados fue de incremento de las acciones, así, entre 1996 y 1997 hubo una ofensiva que dejo más de 50 asesinatos y en los años sucesivos, aunque con altibajos, fue oscilando entre 15 y 20 asesinatos anuales, con una tendencia continuada a la baja, hasta los menos de 5 en 2008. Cabe destacar que "el $17.4 \%$ de los casos fueron atribuidos operaciones conjuntas de la fuerza pública y los paramilitares".

Desgraciadamente, el accionar conjunto de las denominadas Autodefensas Campesinas (paramilitares) y las Fuerzas Armadas del Estado resulta demasiado habitual. El propio Ejército Nacional en muchas ocasiones no lleva los distintivos que el Derecho Internacional Humanitario obliga, de tal forma que realizan actuaciones al margen de la ley accionando como paramilitares. Así se muestra en el vídeo e informe de la ONG International Peace Observatory (IPO), dedicada al acompañamiento físico de personas amenazadas y perseguidas en Colombia. En un acompañamiento y capacitación realizado en el Catatumbo, al nordeste del departamento de Santander, en uno de los mencionados Refugios Humanitarios creado en 2010; el ejercito realizó una incursión sin distintivos que les identificaran y que fue paralizada por la intervención de dicha ONG con su presencia directa y la denuncia de la violación del DIH.

En definitiva, como marcan sus propios estatutos: "Las Comunidades de Paz se presentan como una respuesta a la necesidad de la población civil de establecer mecanismos frente a los actores armados que desarrollen en derecho Internacional Humanitario en busca de su propia protección", a lo que cabría añadir, que resulta la única alternativa real, pragmática, ante el desplazamiento forzoso; un modo de resistencia civil, de autodeterminación para la seguridad humana, apoyado por la comunidad civil internacional mediante las ONG y la presión política, que cambia los paradigmas del sujeto responsable del monopolio de la seguridad, pasando el objeto de seguridad, la persona, a ser el sujeto garante de la misma.

\section{Conclusiones}

Como venimos analizando Colombia vive hoy un conflicto que se alarga por más de 50 años y que tiene su origen en las desigualdades sociales, principalmente en la propiedad desigual de la tierra. Aunque, cabe destacar, que la prolongación de dicho conflicto en el tiempo ha traído consigo una multiplicación de factores y causas para el mantenimiento del mismo, o que cuando menos complican su resolución. Es el caso del narcotráfico y el paramilitarismo que, si bien hoy se supone desmovilizado, continúa bajo la denominación de "Bacrim" (acrónimo de Bandas Criminales) con modos de actuación similares a los denominados "señores de la guerra". Todo ello tiene una incidencia directa en la Seguridad Humana y en la vulneración general de los Derechos Humanos. Si bien cabe destacar que Colombia cuenta con una legislación en esta materia que podría calificarse como ejemplar, no es menos cierto que se incumple sistemáticamente y que en este territorio se dan las mayores violaciones a los derechos humanos del continente. En Colombia la Fuerza Pública está obligada, por mandato constitucional y recogido incluso en el Código Penal Militar, al cumplimiento del DIH pero, evidentemente, este se vulnera. Buen ejemplo de ello, así como de la impunidad incluso cuando los ojos del mundo entero están situados sobre Colombia, es el rescate de Íngrid Betancourt; secuestrada por las 
FARC y rescatada por el Ejercito Colombiano, aprovechando un negociado intercambio de prisioneros de guerra, utilizando para ello los distintivos de la Cruz Roja Internacional con objetivos militares.

En definitiva, la vulneración de los Derechos Humanos y la Seguridad Humana en Colombia es sistemática y especialmente achacable al propio Estado ya que, entiende esta, lejos del concepto amplio del PNUD, incluso del concepto reducido (seguridad frente al temor), como una excusa para la implementación de la denominada Seguridad Democrática. En gobierno de Uribe Vélez, cosifica los grupos insurgentes, incluyendo en estos a todo tipo de resistencia u oposición civil. Cosificación que le permite deshumanizar al contrario y partiendo de las bases de Seguridad Humana que tenía el primer concepto de Seguridad Democrática implementado en Centroamérica en el contexto de los posconflictos; promover la Seguridad Humana desde el control territorial y la "guerra frente al terror". Parafraseando a Pérez de Armiño "existe riesgo de que los ejércitos y los gobiernos manipulen el concepto (de Seguridad Humana) a fin de justificar una cierta militarización de las gestiones de diferentes problemas". Este securitización de los problemas es lo que hace el gobierno de Uribe, quién convierte en guerrilla y por tanto en problema de seguridad a combatir, cualquier protesta social o problemas derivados de la estratificación social y del reparto inequitativo de los recursos.

Resulta evidente, por tanto, que la Seguridad Democrática aprovecha en marco teórico de la Seguridad Humana para implementación de sus políticas, como se ha demostrado mediante la adopción de este término, originario para la implementación de los procesos de paz característicos de la década de los noventa en Centroamérica. Una vulneración, que tiene especial incidencia en el desplazamiento interno forzado. Colombia es, hoy día, el primer país en número de desplazados internos del mundo, según el último informe (2013) del Centro de Monitoreo del Desplazamiento Interno (IDMC, por sus siglas en inglés), dependiente del ACNUR. Así, el mismo informe dice que:

La crisis de los desplazados internos se ha convertido en una de las peores a nivel mundial, afectando de manera desproporcionada a personas afro-colombianas e indígenas, que conforman uno de los grupos más pobres del país. La protección de las personas desplazadas no ha mejorado desde el 2002 cuando el gobierno del Presidente Uribe lanzó una nueva iniciativa bajo su política de "seguridad democrática" para ponerle fin al conflicto a través de tácticas militares.

En realidad, no podría hablarse de que el gobierno colombiano en General, y menos aun el de Uribe en particular, haya contado con una política específica de lucha contra el desplazamiento, más allá de intentar mediante la política de Seguridad Democrática el control de mayor territorio dentro del Estado, garantizando así, según sus tesis, la Seguridad Humana de las personas que los habitan. Pero la realidad es que el propio Estado, mediante esta política es generador de desplazamiento, en ocasiones porque con la llegada del Estado en forma de Fuerzas Armadas, comienzan combates que antes no existían, y en otras, porque el estado cede el uso de la tierra y el territorio "recuperado" a diferentes empresas multinacionales, bajo la excusa de promover así el desarrollo.

En cuanto a las experiencias de resistencia civil frente al desplazamiento, en forma de Comunidades de Paz, suponen una alternativa real para avanzar en la Seguridad 
Humana. Pero aunque es cierto que resultan de especial interés por la implicación del propio objeto de seguridad en sujeto activo de la misma; su incidencia en la sociedad en general es escasa y los datos que arrojan, aunque si bien es cierto que apuntan a una incidencia menor de la violación de los derechos humanos cuando estos consiguen una estabilidad en el tiempo, no es menos cierto que continúan sufriendo vulneración de los mismos en unos índices significativos. Por ello sin llegar a catalogar las experiencias de autogestión de la Seguridad Humana como nuevo paradigma, cabe incidir en que resultan una alternativa real efectiva, para la seguridad, muy probablemente la única hasta la fecha y que puede servir de modelo en el actual proceso de paz entre la guerrilla de las FARC y el Gobierno, en donde ya se está dando espacio a la sociedad civil organizada mediante la Cumbre Agraria que influye en la mesa de tierra que busca que se reviertan los efectos del conflicto, especialmente el desplazamiento forzado. Además el nuevo acuerdo de participación política, permite la participación del movimiento popular mediante el "Estatuto de Oposición", lo que podría otorgar una participación política directa en defensa de sus derechos de estos espacios autogestionados de seguridad Humana.

\section{Bibliografía}

CHURRUCA, C. y MEERTENS, D., (2010) Desplazamiento en Colombia. Prevenir, asistir, transformar. Cooperación Internacional e iniciativas locales, Universidad de Deusto, Bilbao,.

CURREA-LUGO , V., (2008), "Colombia: Derechos Humanos en Crisis", en GÓMEZ ISA, Felipe, Colombia en su laberinto, una mirada al conflicto, Catarata, Madrid, pp. 169-243.

DURÁN, I. M. y VVAA, (2009) “¿Cuales son las ciudades más seguras de Colombia? Propuesta para la estimación de un Índice de Inseguridad Humana”, en RESTREPO, J.A., y APONTE, D., (Ed.), Guerra y violencia en Colombia. Herramientas e interpretaciones, Pontificia Universidad Javeriana, Bogotá, pp. 125-202.

FERNÁNDEZ PEREIRA, J. P., (2006) La Seguridad Humana, un derecho emergente, Ariel, Barcelona.

KAPLAN, R. D., (2007), Gruñidos Imperiales. El imperialismo norteamericano sobre el terreno, Ediciones B, Barcelona.

PÉREZ DE ARMIÑO, K., (2009), "Seguridad humana: el cruce entre la seguridad y el desarrollo", en VVAA, De los derechos y la seguridad humana, de todos o de nadie, Gakoa, Donostia, pp. 19-28.

RAMÍREZ OCAMPO, A., (2004), Conflicto y Seguridad Democrática en Colombia. Temas críticos y propuestas, Fundación Social Friedrich Ebert Stiftung en Colombia, Bogotá.

ROJAS ARAVENA BENÍTEZ, F., (2007), "Seguridad humana: aportes en la reformulación de concepto de seguridad", en SEPÚLVEDA, Isidro, Seguridad Humana y nuevas políticas de Defensa en Iberoamérica, Instituto Universitario "General Gutiérrez Medallo" de Investigación sobre la Paz, la seguridad y la defensa, Madrid, pp. 49-74.

RUEDA, D., (2009 ), “Desterritorialización e inseguridad inhumana. La estrategia de 
mercantilización del territorio", en PÉREZ DE ARMIÑO, Karlos, De los derechos y la seguridad humana, de todos o de nadie, Gakoa, Donostia, pp. 109-136.

SALAMANCA, M. E., (2008), "Un ajedrez del conflicto armado colombiano", en GÓMEZ ISA, Felipe (Coord.), Colombia en su laberinto, una mirada al conflicto, Catarata, Madrid, pp. 17-32.

URRUTIA ASUA, G., (2008), "El desplazamiento forzado, una constante en la generación de víctimas", en GÓMEZ ISA, Felipe (Coord.) Colombia en su laberinto, una mirada al conflicto, Catarata, Madrid, pp. 245-292.

VARGAS VELÁSQUEZ, A., (2007), "La especificidad colombiana: la seguridad democrática", en SEPÚLVEDA, Isidro (Ed.) Seguridad Humana y nuevas políticas de Defensa en Iberoamérica, Instituto Universitario "General Gutiérrez Medallo" de Investigación sobre la Paz, la seguridad y la defensa, Madrid, pp. 121-150.

\section{Fuentes documentales}

- Carta del Presidente de la República Álvaro Uribe "Política de Defensa y Seguridad Democrática", en http://www.resdal.org/Archivo/col-03presi.htmhttp://www.resdal.org/Archivo/col-03-presi.htm

- Centro de Monitoreo del Desplazamiento Interno (IDMC en ingles), informe del 2013, disponible en la página web oficial del ACNUR, disponible en: http://www.acnur.org/t3/fileadmin/scripts/doc.php?file=biblioteca/pdf/2515 http://www. acnur.org/t3/fileadmin/scripts/doc.php?file=biblioteca/pdf/2515

- Evolución anual del desplazamiento en Colombia en la página web de la CODHES, disponible en http://www.codhes.org/index.php?option=com docman\&task=cat view\&gid=55\&ltem id=51http://www.codhes.org/index.php?option=com_docman\&task=cat_view\&gid=55 \&ltemid $=51$

- Informe sobre el desplazamiento en Colombia 2011, ACNUR página oficial, en http://www.acnur.org/t3/operaciones/situacion-colombia/desplazamiento-internoen-colombia/http://www.acnur.org/t3/operaciones/situacion-

colombia/desplazamiento-interno-en-colombia/

- International Peace Observatory (IPO), vídeo de la creación del Campamento Refugio Humanitario del Catatumbo y la incursión del ejercito en la página web de la ONG, disponible en http://blip.tv/ipointernational-peace-observatory/campamentorefugio-humanitario-3557800http://blip.tv/ipointernational-peace-

observatory/campamento-refugio-humanitario-3557800

- "Un programa para la Cumbre Mundial sobre Desarrollo Social", Informe sobre Desarrollo Humano del PNUD de 1994 en Página Oficial PNUD, http://hdr.undp.org/es/informes/mundial/idh1994http://hdr.undp.org/es/informes/mund ial/idh1994/

- $\quad$ Red de Hermandad y Solidaridad con Colombia, informe 2011, disponible en página oficial de la Red de Hermandad $y$ Solidaridad con Colombia http://www.redcolombia.org/index.php/buscar-

men.html?searchword=datos\%20guerra\&ordering=newest\&searchphrase=all\&limit=2 Ohttp://www.redcolombia.org/index.php/buscar-men.html?searchword=datos guerra\&ordering=newest\&searchphrase=all\&limit=20

Retratos de la Colombia en Guerra, 2010, programa En Portada, en la página oficial 